\title{
FATORES ASSOCIADOS A SÍNDROME DE BURNOUT EM PROFESSORES
}

\section{FACTORS ASSOCIATED WITH BURNOUT SYNDROME IN TEACHERS}

\section{FACTORES ASOCIADOS EL SÍNDROME DE BURNOUT EN PROFESORES}

Maria Iasmin Lopes Ramalho, Universidade Federal de Campina Grande (UFCG), iasminlopesramalho@gmail.com

Hélida Maravilha Dantas e Sousa Almeida, Universidade Federal de Campina Grande (UFCG),

helidacaico@hotmail.com

Paula Frassinetti Oliveira Cezário, Universidade Federal de Campina Grande (UFCG), paulafrassinetti22@gmail.com

PALAVRAS-CHAVE: Fatores de Risco; Síndrome de Burnout; Professores; KEY WORDS: Risk Factors; Burnout syndrome; Teachers; PALABRAS CLAVE: Factores de riesgo; Síndrome de Burnout; Profesores;

\section{INTRODUÇÃO}

As principais características definidoras da Síndrome de Burnout são a exaustão emocional, na qual o trabalhador apresenta a sensação de esgotamento de recursos, e ausência de energia para a execução de atividades laborais; a despersonalização que caracteriza-se pela ausência de humanização nas relações estabelecidas entre o trabalhador e os indivíduos que fazem parte do seu meio de trabalho; a diminuição da realização pessoal com a profissão que é determinado pelo sentimento de infelicidade e insatisfação profissional. Assim, os indivíduos que apresentam a SB possuem uma produtividade diminuída nas 
execuções de atividades laborais, bem como denotam maior probabilidade para 0 desenvolvimento de agravos a saúde física e mental das pessoas (MESQUITA, et al. 2013).

Os professores caracterizam-se como uma categoria propicia a desenvolver a Síndrome de Burnout, uma vez que muitos professores vivenciam diariamente extensas horas de serviços e em algumas situações são remunerados de forma inadequada, existe a desvalorização profissional, as condições de trabalho e a infraestrutura muitas vezes são precárias o que pode resultar em prejuízos a saúde mental dos docentes. Diante da importância da temática exposta, o presente estudo tem como objetivo desenvolver um levantamento bibliográfico para identificar, na literatura cientifica, os principais fatores de risco para a Síndrome de Burnout em professores.

\section{METODOLOGIA}

Trata-se de uma revisão integrativa da literatura com abordagem qualitativa. $\mathrm{O}$ levantamento bibliográfico foi realizado no mês de junho de 2017 nas bases de dados Latin American Literature in Health Sciences (LILACS), Indice Bibliográfico Español de Ciencias de la Salud (IBECS), Literatura Internacional em Ciências da Saúde (MEDLINE), Index Psi Periódicos Técnico-Científicos e Scientific Eletronic Library Online (SCIELO), via Biblioteca Virtual de Saúde, utilizando os descritores "fatores de riscos", "síndrome de burnout", "professores" e o operador booleano AND, no intuito de responder a seguinte questão norteadora: "Quais os fatores de risco para o desenvolvimento da Síndrome de Burnout em professores?". Quanto aos critérios de inclusão foram incluídos artigos disponíveis na íntegra, publicados entre 2010 a 2016, nos idiomas português, espanhol e inglês que abordavam a temática proposta. Os critérios de exclusão foram artigos incompletos, duplicados, incompatíveis com a temática descrita, teses, relatos de caso e dissertações. A pesquisa foi constituída por 23 publicações que abordavam o tema exposto, dos quais foram selecionados para compor o estudo 7 artigos, considerando os critérios de inclusão e exclusão.

\section{DESCRIÇÕES, RESULTADOS, INTERPRETAÇÕES}

Conforme estudos desenvolvidos por Diehl e Carlotto (2014) os principais fatores desencadeantes da síndrome de burnout em professores estão relacionados à indisciplina dos 
alunos, falta de apoio dos pais e da direção da escola, sobrecarga de trabalho, cobrança social. Para Andrade e Cardoso (2012) as causas de riscos para o Burnout são o envolvimento dos docentes com os alunos, inadequação entre formação e desenvolvimento profissional e remuneração salarial baixa. Esses achados condizem com outras pesquisas realizadas por Roupp e Justen (2016) que apontam à falta de estabilidade no emprego, baixa valorização profissional e pouco apoio das instituições de ensino, baixa qualidade de vida dos professores, alta carga horária de trabalho, excesso de tarefas realizadas fora do ambiente escolar, doenças crônicas desenvolvidas em decorrência da atividade laboral como os fatores responsáveis pelo surgimento da síndrome de Burnout em docentes. Além dos elementos apontados pelos pesquisadores citados anteriormente como causas predisponentes para a síndrome de Burnout, Mesquita et al. (2013) destaca a indisciplina, violência e desinteresse do alunado, a ausência de material didático, superlotação das turmas e a gestão escolar inadequada. No entanto, os estudos realizados por Espinoza-Díaz, Tous-Pallares e Vigil-Colet (2015) divergem em alguns pontos com as pesquisas citadas anteriormente e apontam elementos relacionados a personalidade, estabilidade emocional e amabilidade dos docentes como causas que interferem significativamente no desenvolvimento da síndrome de Burnout. Os achados do estudo de CORREA e ZAMBRANO (2010) e Carlotto (2011) assemelham-se quantos as causas associadas ao Burnout em docentes e apontam a despersonalização, exaustão emocional, atitudes negativas e baixa realização profissional como elementos importantes.

\section{CONSIDERAÇÕES FINAIS}

Diante das informações expostas nessas pesquisas constatamos que elementos relacionados a personalidades, as condições de trabalho dos professores, bem como as relações estressantes estabelecidas entre o alunado e as instituições de ensino são elementos que merecem intervenções para serem solucionados, uma vez que a identificação desses fatores é essencial para o estabelecimento de medidas que diminuam os níveis de estresse, concomitante ações que garanta medidas preventivas aos professores contra a síndrome de Burnout, pois dessa forma ocorreria benefícios na saúde mental dos professores incidindo na melhoria da vida pessoal, bem como na qualidade do ensino.

\section{REFERÊNCIAS}


ANDRADE,S.P.; CARDOSO,O.A.T. Prazer e Dor na Docência: revisão bibliográfica sobre a Síndrome de Burnout. Saúde Soc. São Paulo, v.21, n.1, p.129-140, 2012. Disponível em: http://www.scielo.br/scielo.php?script=sci_arttext\&pid=S0104-12902012000100013. Acesso em:10 jul 2017.

CARLOTTO,M.S. Síndrome de Burnout em Professores: Prevalência e Fatores Associados. Psicologia: Teoria e Pesquisa.Brasília,v.27,n.4,p.403-410, Out-Dez 2011. Disponível em: $\quad$ http://www.scielo.br/scielo.php?script=sci_arttext\&pid=S010237722011000400003. Acesso em:10 jul 2017.

CORREA,C.Z.;ZAMBRANO,M.I. Síndrome de Burnout en docentes de dos universidades de Popayán, Bogotá. Revista Salud Pública.Colômbia, v.12, n..4,agosto,2010. Disponível em: http://www.scielo.org.co/scielo.php?script=sci_arttext\&nrm=iso\&lng=pt\&tlng=pt\&pid=S012 4-00642010000400006. Acesso: 10 Jul 2017.

DIEHL, L.; CARLOTTO, M. S. Conhecimento de Professores sobre a Síndrome de Burnout: processo, fatores de risco e consequências. Psicol. estud., Maringá , v. 19, n. 4, p. 741-752, $\quad$ Dec. $2014 \quad$. $\quad$ Available from $<$ http://www.scielo.br/scielo.php?script=sci_arttext\&pid=S141373722014000400741\&lng=en\&nrm=iso>. access $\quad$ on $\quad 03 \mathrm{Jul} . \quad 2017$. http://dx.doi.org/10.1590/1413-73722455415.

ESPINOZA-DIAZ, I.M.; TOUS-PALLARES, J.; VIGIL-COLET, A. Efecto del Clima Psicosocial del Grupo y de la Personalidad en el Síndrome de Quemado en el Trabajo de los docentes. Anal. Psicol., Murcia , v. 31, n. 2, p. 651-657, mayo 2015 . Disponible en $<$ http://scielo.isciii.es/scielo.php?script=sci_arttext\&pid=S021297282015000200029\&lng=es\&nrm=iso>. accedido en 29 jul. 2017. http://dx.doi.org/10.6018/analesps.31.2.174371.

MESQUITA, A.A; et al. Estresse e síndrome de burnout em professores: Prevalência e causas. Maranhão: Psicologia Argumento, v.31, n.75, 2013. Disponível em: 
http://www2.pucpr.br/reol/pb/index.php/pa?dd1=12630\&dd99=view\&dd98=pb.

Acesso em:10 jul 2017.

ROUPP, L.M; JUSTEN, D.E. Síndrome de Bournout em professores do ensino médio: um estudo qualitativo baseado no modelo biográfico de Kelchtermans. Canoas: Barbarói, $\mathrm{N}^{\circ}$ 46 ANO 2016/1. Disponível em: http://dx.doi.org/10.17058/barbaroi.v0i46.7391. Acesso em:10 jul 2017. 